\title{
Military Healthcare Providers' Knowledge and Comfort Regarding the Medical Care of Active Duty Lesbian, Gay, and Bisexual Patients
}

\author{
Caitlyn M. Rerucha, MD, ${ }^{1,2}$ Lloyd A. Runser, MD, MPH, ${ }^{1,3}$ \\ Juliana S. Ee, PhD, and Elizabeth G. Hersey, DO ${ }^{1,4}$
}

\begin{abstract}
Purpose: This study assessed military healthcare providers' knowledge, clinical practice, and comfort in caring for active duty (AD) lesbian, gay, and bisexual (LGB) patients.

Methods: Primary care providers at Fort Bragg, North Carolina were surveyed anonymously.

Results: The response rate was $28 \%(n=40)$. Almost two-thirds of the respondents felt comfortable discussing sexual health with AD patients, but only 5\% inquired about same-sex sexual activity. Slightly less than one-third reported prior training in LGB healthcare topics and nearly four-fifths desired clear guidance from the Department of Defense regarding the process for screening and documentation of AD same-sex sexual activity.
\end{abstract}

Conclusion: The findings highlight providers' need and desire for training in LGB patient care.

Keywords: attitudes, bisexual, gay, lesbian, military, provider

\section{Introduction}

T He WiLliams Institute estimated, in a 2010 research brief, that $\sim 2 \%$ of active duty (AD) military personnel identified as lesbian, gay, and bisexual (LGB). ${ }^{1}$ In 2011, the Department of Defense's (DoD) "Don't Ask, Don't Tell" (DADT) policy was repealed, allowing LGB soldiers to serve openly in the US military. ${ }^{2}$ To date, there is a paucity of research that explores the impact of the DADT repeal on healthcare delivery to AD LGB patients.

Health disparities for American LGB youth and adults are well documented ${ }^{3}$; however, there are fewer data specific to LGB servicemembers. ${ }^{4-6}$ Barriers to optimal healthcare for LGB individuals include stigma, discrimination, invisibility, and hesitancy to disclose their sexual behaviors to providers and others. ${ }^{7-9}$ Providers may add to these barriers due to their discomfort in asking about sexual orientation and their lack of knowledge regarding health issues specific to LGB populations. ${ }^{9}$ Thus, it is important for military providers to be knowledgeable about the sexual and mental health needs of their $\mathrm{AD}$ LGB patients to provide appropriate preventive screening. The aim of this study was to examine healthcare providers' current knowledge, clinical practice, and comfort level pertaining to AD LGB patients after the DADT policy repeal.

\section{Methods}

An online anonymous survey was distributed electronically between September and October 2014 to a convenience sample of 145 physicians, resident physicians, nurse practitioners, physician assistants, and general practitioners that provide primary care to AD LGB soldiers stationed at Fort Bragg, North Carolina. Voluntary participation was emphasized. Consent to participate in the study was implied by completing the online survey. All responses were confidential and anonymous. The Womack Army Medical Center Institutional Review Board approved this study.

The research team developed the 33-item survey instrument (relevant validated measures were not otherwise available). Survey questions assessed providers' knowledge of Centers for Disease Control and Prevention

\footnotetext{
${ }^{1}$ Family Medicine Residency Program, Department of Family Medicine, Womack Army Medical Center, Fort Bragg, North Carolina.

${ }^{2}$ Present affiliation: Family Medicine Residency Program, Department of Family and Community Medicine, Carl R. Darnall Army Medical Center, Fort Hood, Texas.

${ }^{3}$ Present affiliation: Department of Family Medicine, Novant Health Family Medicine Residency, Charlotte, North Carolina.

${ }^{4}$ Present affiliation: Department of Family Medicine, Womack Army Medical Center, Fort Bragg, North Carolina.

(c) Caitlyn M. Rerucha et al. 2017; Published by Mary Ann Liebert, Inc. This is an Open Access article distributed under the terms of the Creative Commons Attribution License, which permits unrestricted use, distribution, and reproduction in any medium, provided the original work is properly cited.
} 
(CDC) recommendations and health issues unique to LGB patients, their comfort level in addressing the sexual health needs of AD LGB patients, their training on LGB healthcare and exposure to caring for LGB patients, and basic demographic information, including years in clinical practice (5 or more years were categorized as "senior providers").

The knowledge questions referenced CDC 2010 guidelines for sexually transmitted infection (STI) screening ${ }^{10}$ and Healthy People 2020 for LGB epidemiologic healthrelated issues. ${ }^{11}$ Knowledge questions were measured using "True," "False," and "Don't Know" options. Comfort level items were modified from the attitude scale in Sanchez et al. ${ }^{12}$ and were measured using a 5-point Likert scale, from strongly disagree to strongly agree. Current exposure to LGB patient care and demographics questions were modified from the Tong et al. survey. ${ }^{4}$ A free-text box was provided for respondents' general comments.

Data analyses were performed using IBM SPSS Statistics, version 22 (IBM Corporation, Armonk, NY). Descriptive statistics were computed for demographic variables. Independent sample $t$-test was used to examine differences between the groups, and chi-square test was used to examine relationships for categorical variables. All analyses were two tailed with $\alpha=0.05$.

\section{Results}

Forty-one providers completed the online survey; however, data from one survey from a psychologist were excluded (28\% response rate; $n=40$ ). Demographic information is summarized in Table 1.

\section{Provider knowledge, prior training, and seniority of clinical practice}

As shown in Table 2, only 53\% of the respondents correctly identified the CDC-recommended screening examinations for sexually active men who have sex with men (MSM), $68 \%$ correctly indicated that the $\mathrm{CDC}$ recommends hepatitis A vaccination series for all MSM, and only $35 \%$ answered correctly that an annual anal Papanicolaou (Pap) test for sexually active MSM is not recommended (unless the patient has a history of human immunodeficiency virus [HIV] infection). Mean number of correct responses for the three CDC MSM questions was 1.55 (standard deviation $[\mathrm{SD}]=0.88$ ). Sixty-three percent of respondents showed positive knowledge that MSM compared to heterosexual men, have different risk for developing STIs and 48\% correctly recognized that Black MSM represent the fastest growing demographic of new HIV infections. The vast majority $(95 \%)$ knew that sexually active women who have sex with women (WSW) have the same cervical cancer screening guidelines as heterosexual women. Only $13 \%$ of respondents correctly indicated that WSW, compared to women who only have sex with men, have higher rates of tobacco use. About half (55\%) said that LGB patients, compared to same age and gendered heterosexual patients, have higher rates of depression. Mean number of correct responses for the five LGB health-related questions was $2.76(\mathrm{SD}=1.18)$.

Slightly less than one-third reported that they have received medical training regarding optimal healthcare for LGB patients (Table 1), and nearly four-fifths desired clear guidance from the DoD regarding the process for screening
Table 1. Demographic Characteristics of Survey RESPONDENTS $(n=40)$

\begin{tabular}{|c|c|}
\hline & $\mathrm{n}(\%)$ \\
\hline \multicolumn{2}{|l|}{ Gender } \\
\hline Male & $26(65)$ \\
\hline Female & $11(28)$ \\
\hline Missing & $3(8)$ \\
\hline \multicolumn{2}{|l|}{ Level of training } \\
\hline Attending physician (MD, DO) & $18(45)$ \\
\hline Resident physician (MD, DO) & $6(15)$ \\
\hline Mid-level provider (RN, NP, PA) & $12(30)$ \\
\hline Missing & $4(10)$ \\
\hline \multicolumn{2}{|l|}{ Specialty } \\
\hline Family medicine & $23(58)$ \\
\hline Primary care or general practice & $6(15)$ \\
\hline General medical officer at clinic & $4(10)$ \\
\hline General medical officer at unit & $2(5)$ \\
\hline $\begin{array}{l}\text { Operational medicine (aviation, } \\
\text { special operations) }\end{array}$ & $1(2)$ \\
\hline Missing & $4(10)$ \\
\hline \multicolumn{2}{|l|}{ AD or civilian } \\
\hline Civilian (with prior AD service) & $6(5)$ \\
\hline Civilian (no prior AD service) & $1(2)$ \\
\hline $\mathrm{AD}$ & $31(78)$ \\
\hline Reserve or National Guard & $0(0)$ \\
\hline Missing & $2(5)$ \\
\hline \multicolumn{2}{|l|}{ Years in medical practice } \\
\hline Junior providers & $22(55)$ \\
\hline Currently in training/residency & $2(5)$ \\
\hline Less than 2 years & $9(22)$ \\
\hline 2-4 Years & $11(28)$ \\
\hline Senior providers & $15(38)$ \\
\hline $5-10$ Years & $9(23)$ \\
\hline More than 10 years & $6(15)$ \\
\hline Missing & $3(7)$ \\
\hline \multicolumn{2}{|l|}{ Prior training in LGB care } \\
\hline Yes & $12(30)$ \\
\hline No & $25(63)$ \\
\hline Missing & $3(7)$ \\
\hline
\end{tabular}

Types of prior LGB training if "yes" (respondents checked all that apply, $n=12$ )

Lectures in RN, NP, PA, or medical school

Postgraduate training $\quad 5 / 12(42)$

Online CME 4/12 (33)

Professional journals 3/12 (25)

Professional conferences $\quad 1 / 12(8)$

$\mathrm{AD}$, active duty; CME, continuing medical education; $\mathrm{DO}$, doctor of medicine, osteopathic physician; LGB, lesbian, gay, and bisexual; $\mathrm{MD}$, doctor of medicine, allopathic physician; NP, nurse practitioner; PA, physician's assistant; RN, registered nurse.

and documentation of AD same-sex sexual activity $(n=31 /$ 40, data not shown). Comparing providers with and without prior training showed no relationship between prior training and provider correct responses on the three CDC questions $(\mathrm{M}=1.58$ vs. $1.60, P>0.05)$ or on the five LGB healthrelated questions $(\mathrm{M}=3.18$ vs. $2.68, P>0.05)$. No difference was found between junior and senior providers' number of correct responses on the three $\mathrm{CDC}$ questions $(\mathrm{M}=1.55$ vs. 1.67 ; $P>0.05$ ); however, junior providers were significantly less knowledgeable than senior providers on the five LGB healthrelated questions ( $\mathrm{M}=2.47$ vs. $3.33, P=0.03$ ). 
Table 2. Correct Response Frequency of Knowledge Item $(n=40)$

n $(\%)$

CDC guidelines for MSM ${ }^{\mathrm{a}}$

All of the following screening examinations are recommended by the CDC annually for sexually active MSM: HIV, syphilis, hepatitis, gonorrhea, and chlamydia testing of the urethra, oropharynx, and rectum ${ }^{b}$

The CDC recommends hepatitis A vaccination series for all MSM $^{\mathrm{b}}$

The CDC recommends annual anal Papanicolaou smear for sexually active MSM $^{\mathrm{c}}$

LGB health questions

WSW use tobacco more than women who only have sex with men ${ }^{\mathrm{b}}$

LGB patients have higher rates of depression compared to heterosexual patients of same age and sex ${ }^{\mathrm{b}}$

The same cervical cancer screening guidelines are used for sexually active WSW and heterosexual women ${ }^{\mathrm{b}}$

Black MSM represent the fastest growing demographic of new HIV infections ${ }^{b}$

MSM have the same risks for developing sexually transmitted infections as heterosexual men ${ }^{c}$

Response options were “True," "False," and "Don't Know." Answer was considered incorrect if respondent marked "Don't Know."

${ }^{a}$ Centers for Disease Control and Prevention (2014).

${ }^{\mathrm{b}}$ Correct answer for this question was "True."

"Correct answer for this question was "False."

CDC, Centers for Disease Control and Prevention; HIV, human immunodeficiency virus; MSM, men who have sex with men; WSW, women who have sex with women.

\section{Exposure to $L G B$ patient care}

Only $5 \%$ of the respondents "routinely obtain sexual history, including questions pertaining to same-sex sexual activity from AD service members." Fifty-three percent reported that they have cared for one or more AD MSM in the past 12 months, and $61 \%$ reported that they have cared for one or more $\mathrm{AD}$ WSW during the same period. Almost one-third of respondents admitted that they are "not sure" about their AD patients' sexual activities in the past 12 months or "haven't asked" about their AD patients' sexual activities in the past 12 months. Thus, they are unsure if they have provided care to AD MSM or WSW patients. Likewise, when the respondents were asked specifically if they have cared for AD bisexual patients in the past 12 months, 53\% indicated that they were "not sure" or "haven't asked" about their AD patients' sexual activities in the past 12 months, so were unsure if they had cared for bisexual patients. In contrast, an overwhelming majority (90\%) knew that DoD does not prohibit asking patients about same-sex sexual activity. No significant difference was found between providers with and without exposure to LGB patient care in terms of the number of correct answers for the three CDC questions ( $\mathrm{M}=1.57$ vs. 1.58 ,
$P>0.05)$ or the five LGB health-related questions ( $\mathrm{M}=2.80$ vs. 2.83, $P>0.05)$.

\section{Provider comfort level and attitudes}

Provider comfort level was assessed with five items using a strongly disagree to strongly agree 5-point Likert scale; higher scores represent greater comfort level. Two items were reverse scored. As shown in Table 3, providers had an overall mean comfort level score of $3.90(\mathrm{SD}=0.67$, range $=2.60-5.00) ; 60 \%$ feel comfortable discussing and assessing the sexual health needs of AD LGB patients; $65 \%$ are as comfortable taking a complete sexual history from AD MSM as they are with AD heterosexual men; and $63 \%$ indicated likewise when working with AD WSW. More than four-fifths indicated that they disagree that it is more challenging to conduct a genitourinary examination on an AD MSM patient $(88 \%)$ or an AD WSW patient (92\%) compared to a perceived $\mathrm{AD}$ heterosexual patient. Notably, compared to senior providers, junior providers reported significantly higher mean comfort level (3.61 vs. 4.15; $P=0.016)$.

Table 3. Means and Standard Deviations of Comfort Level Ratings

Comfort level Mean (SD)

I am comfortable discussing and assessing the sexual health needs of AD LGB patients. $3.64(0.90)$

I am as comfortable taking a complete sexual history from AD MSM as I am with AD heterosexual men.

I am as comfortable taking a complete sexual history from AD WSW as I am with AD

$3.62(1.07)$ heterosexual women.

It is more challenging for me to conduct a genitourinary examination on an AD MSM patient than an AD heterosexual male patient. ${ }^{\mathrm{b}}$

It is more challenging for me to conduct a genitourinary examination on an AD WSW patient than an AD heterosexual female patient. ${ }^{b}$

Comfort level average score over 5 items

$3.67(1.01)$

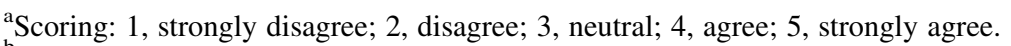

${ }^{\mathrm{b}}$ Reverse scored.

$\mathrm{SD}$, standard deviation. 


\section{Discussion}

AD LGB individuals have unique sexual and mental health needs and are at increased risk for certain chronic diseases. ${ }^{13,14}$ It is best practice for military clinicians to assess sexual preferences and behaviors; failure to do so worsens health disparities. Providers must identify and remove barriers to culturally sensitive care and create supportive clinical environments in which AD sexual minority patients can share health information. Primary care clinicians must know and feel confident to implement current recommendations for LGB patients such as the CDC recommendations for MSM screening tests among others. Although more respondents (53\%) correctly identified the CDC STI screening recommendations for MSM in this study compared to the Tong et al. study, ${ }^{4}$ nearly half of the clinicians were still uninformed on this topic.

To the best of our knowledge, this is the first study to explore military primary care providers' perception of the healthcare needs of AD WSW. A vast majority of the providers were knowledgeable about current Pap test guidelines for WSW. The most concerning finding from our study was that only $5 \%$ of respondents routinely obtain sexual history, including questions about same-sex sexual activities, despite more than $90 \%$ reporting that they know they are not prohibited from asking about same-sex sexual activity. Thus far, factors that affect military healthcare providers' decisionmaking about assessing sexual behaviors have not been examined specifically; however, a study of Veterans Health Affairs (VHA) providers found that the decision to assess sexual orientation is multifactorial and only $10 \%$ of VHA providers reported that they ask this of all of their patients. ${ }^{15}$

With recent DoD Instruction $1300.28,{ }^{16}$ there has been a new initiative to educate military providers about transgender issues; however, sexual minority health remains largely invisible. LGB health training in the DoD is typically sought out by individual providers based on personal interest and is not required or standardized. Consolidated Veterans Affairs (VA)/ DoD clinical practice guidelines, such as those currently available for chronic pain and diabetes management, ${ }^{17}$ would assist in educating military clinicians about LGB health. One survey respondent commented as follows: "please distribute consensus guidelines on health screening for MSM" and further noted that having guidelines "would be helpful for all operational physicians/physician assistants at the unit level.'

The Institute of Medicine recommends the collection of sexual orientation data in electronic medical records (EMR). ${ }^{18}$ Thus, one avenue to increase collection of sexual orientation data in the DoD is to add nonjudgmental sexual history questions to the DoD EMR templates. AD patients will need to trust that this sensitive information remains confidential and protected, and staff will need to ensure that the information is genuinely used to improve the quality of healthcare delivered. ${ }^{19}$ Callahan et al. insist that staff are trained carefully before implementation. ${ }^{20}$

Less than one-third of respondents had ever received medical training on LGB health topics. This is not surprising to the authors, taking into consideration that an average of only 5 hours of the US medical education curricula is devoted to teaching lesbian, gay, bisexual, and transgenderrelated content ${ }^{21,22}$; the DoD does not offer this specific training currently. Lack of knowledge likely leads many providers to feel ill-equipped to meet the healthcare needs of sexual minority patients. The desire for more training is echoed in these comments: "More guidance from the DoD is necessary, and more training is strongly advised. With more education, biases and prejudices decrease" and "formal training on care of LGB patients would be extremely helpful. Please be sure to put out to all providers if that is something that happens on Fort Bragg."

Respondents generally felt comfortable with caring for their AD LGB patients, including discussing and assessing sexual health needs and performing clinical examinations. Junior providers, including resident physicians, had higher overall mean comfort ratings; this may be due to recent efforts in graduate medical education to focus on cultural competency and healthcare disparities assessments ${ }^{23}$ or having personal relationships with LGB friends or family members. ${ }^{15}$

This study has several limitations. First, the response rate was low. Factors likely affecting the response rate are availability of clinicians due to deployments and summer relocations or opting out due to personal feelings about the topic. Second, the survey was distributed at a single US Army installation, so generalizability is limited. Future larger scale studies at multiple military locations should be considered to increase applicability of the findings. Finally, some of the survey items do not have validated psychometric properties (due to the lack of existing established measures in the literature).

\section{Conclusion}

The Military Health System (MHS) needs to undertake initiatives to ensure the delivery of culturally attuned AD LGB healthcare. Robust education efforts similar to those recently implemented for MHS transgender care are recommended. Persistent ignorance of the unique healthcare needs of AD LGB soldiers by military providers has implications for readiness and resiliency. Future research should focus on the creation of evidence-based clinical practice guidelines to improve the knowledge and practice of healthcare providers taking care of AD LGB patients. AD MSM health is addressed in a recent publication ${ }^{6}$; however, recommendations for AD bisexual men and women and WSW need to be added. Primary care's routine assessment of sexual behaviors must be improved to ensure that AD LGB patients do not remain invisible despite DADT repeal.

\section{Acknowledgments}

The authors thank the Womack Army Medical Center Department of Clinical Investigation, including Cristobal S. Berry-Caban, $\mathrm{PhD}$, for his assistance with finalizing this article. There was no funding or additional support for this study.

\section{Disclaimer}

The views expressed herein are those of the author(s) and do not reflect the official policy of the Department of the Army, DoD, or the US Government.

\section{Author Disclosure Statement}

No competing financial interests exist.

\section{References}

1. Gates GJ: Lesbian, gay, and bisexual men and women in the US military: Updated estimates. The Williams Institute, 
May 2010. Available at http://williamsinstitute.law.ucla .edu/wp-content/uploads/Gates-GLBmilitaryUpdate-May20101.pdf Accessed August 7, 2016.

2. Stanley CL: Memorandum for secretaries of the military departments; subject: Repeal of Don't Ask, Don't Tell and future impact on policy. January 28, 2011. Available at http:// archive.defense.gov/home/features/2010/0610_dadt/USD-PRDADT_28Jan11.pdf Accessed May 1, 2017.

3. Ard KL, Makadon HJ: Improving the health care of lesbian, gay, bisexual and transgender (LGBT) people: Understanding and eliminating health disparities. Boston. MA: The National LGBT Health Education Center, The Fenway Institute, 2012. Available at www.lgbthealtheducation.org/ wp-content/uploads/12-054_LGBTHealtharticle_v3_07-09-12 .pdf Accessed August 7, 2016.

4. Tong RL, Lane J, McCleskey P, et al.: A pilot study describing knowledge and practices in the health care of men who have sex with men by U.S. Air Force primary care providers. Mil Med 2013;178:e248-e254.

5. Biddix JM, Fogel CI, Perry Black B: Comfort levels of active duty gay/bisexual male service members in the military healthcare system. Mil Med 2013;178:1335-1340.

6. Campbell WR, Jahan M, Bavaro MF, Carpenter RJ: Primary care of men who have sex with men in the U.S. Military in the post-Don't Ask, Don't Tell era: A review of recent progress, health needs, and challenges. Mil Med 2017; 182:e1603-e1611.

7. Mayer KH, Bradford JB, Makadon HJ, et al.: Sexual and gender minority health: What we know and what needs to be done. Am J Public Health 2008;98:989-995.

8. Ramchand R, Fox CE: Access to optimal care among gay and bisexual men: Identifying barriers and promoting culturally competent care. In: Unequal Opportunity: Health Disparities Affecting Gay and Bisexual Men in the United States. Edited by Wolitski RJ, Stall R, Valdiserri RO. New York, NY: Oxford University Press, 2007:355-378.

9. Mravcak SA: Primary care for lesbians and bisexual women. Am Fam Physician 2006;74:279-286.

10. Centers for Disease Control and Prevention. Special populations: Sexually transmitted diseases treatment guidelines, 2010. Last updated August 2014. Available at www.cdc .gov/std/treatment/2010/specialpops.htm Accessed January $1,2015$.

11. Healthy People 2020. Lesbian, gay, bisexual, and transgender health. Washington, DC: U.S. Department of Health and Human Services. Available at www.healthypeople.gov/2020/ topics-objectives/topic/lesbian-gay-bisexual-and-transgenderhealth Accessed January 1, 2015.

12. Sanchez NF, Rabatin J, Sanchez JP, et al.: Medical students' ability to care for lesbian, gay, bisexual, and trangendered patients. Fam Med 2006;38:21-27.

13. Gonzales G, Przedworski J, Henning-Smith C: Comparison of health and health risk factors between lesbian, gay, and bisexual adults and heterosexual adults in the United States. Results from the National Health Interview Survey. JAMA Intern Med 2016;176:1344-1351.

14. [No authors listed]: Health care needs of gay men and lesbians in the United States. Council on Scientific Affairs, American Medical Association. JAMA 1996;275:1354-1359.

15. Sherman MD, Kauth MR, Shipherd JC, Street RL, Jr: Provider beliefs and practices about assessing sexual orientation in two Veterans Health Affairs hospitals. LGBT Health 2014;1:185-191.

16. Department of Defense. DoD Instruction 1300.28 in-service transition for transgender service members. 2016. Available at www.defense.gov/Portals/1/features/2016/0616_policy/ DoD-Instruction-1300.28.pdf Accessed May 6, 2017.

17. U.S. Department of Veterans Affairs: VA/DoD clinical practice guidelines. Available at www.healthquality.va.gov Accessed May 8, 2017.

18. Institute of Medicine (US) Committee on Lesbian, Gay, Bisexual, and Transgender Health Issues and Research Gaps and Opportunities: The Health of Lesbian, Gay, Bisexual, and Transgender People: Building a Foundation for Better Understanding. Washington, DC: National Academies Press, 2011.

19. McNair RP, Hegarty K: Guidelines for the primary care of lesbian, gay, and bisexual people: A systematic review. Ann Fam Med 2010;8:533-541.

20. Callahan EJ, Hazarian S, Yarborough M, Sánchez JP: Eliminating LGBTIQQ health disparities: The associated roles of electronic health records and institutional culture. Hastings Cent Rep 2014;44(Suppl. 4):S48-S52.

21. Lapinski, J, Sexton, P, Baker L: Acceptance of lesbian, gay, bisexual, and transgender patients, attitudes about their treatment, and related medical knowledge among osteopathic medical students. J Am Osteopath Assoc 2014;114: 788-796.

22. Obedin-Maliver J, Goldsmith ES, Stewart L, et al.: Lesbian, gay, bisexual, and transgender-related content in undergraduate medical education. JAMA 2011;306:971-977.

23. Maldonado ME, Fried ED, DuBose TD, et al.: The role that graduate medical education must play in ensuring health equity and eliminating health care disparities. Ann Am Thorac Soc 2014;11:603-607.

Address correspondence to: Caitlyn M. Rerucha, MD Family Medicine Residency Program Department of Family and Community Medicine Carl R. Darnall Army Medical Center 36065 Santa Fe Avenue Fort Hood, TX 76544

E-mail: cmreruchamd@gmail.com 